\title{
Los pastos de montaña de la Sierra del Aramo (Macizo Central Asturiano): análisis geoecológico, evolución histórica y dinámica reciente
}

\author{
Salvador Beato Bergua \\ José Luis Marino Alfonso \\ Miguel Ángel Poblete Piedrabuena \\ Universidad de Oviedo. Departamento de Geografía \\ beatosalvador@uniovi.es \\ jolumarino@gmail.com \\ mpoblete@uniovi.es
}

Raquel Cunill Artigas

José Manuel Rodríguez Berdasco

Profesionales autónomos

cunillraquel@gmail.com

jmberdasko@hotmail.com

Recibido: mayo de 2020

Aceptado: septiembre de 2020

Publicado: enero de 2021

\section{Resumen}

Se analizan los pastizales montanos y subalpinos de la Sierra del Aramo, bastión calcáreo del Macizo Central Asturiano, centrándose no solo en el estado y la composición de las formaciones pratenses, sino también en su origen y devenir histórico, especialmente en la dinámica actual. Las metodologías empleadas incluyen, entre otras, el estudio florístico y fitosociológico, la cartografía de cubiertas vegetales y hábitats de interés comunitario de porte herbáceo, el ensayo de la pedoantracología y técnicas historicistas. Como resultado, se han caracterizado los pastos montanos y subalpinos, así como cartografiado la distribución de los hábitats herbáceos 6170, 6210, 6230, 6510, 8130 y 8210, y ha quedado establecida la expansión de los pastos en la Edad del Bronce. Así pues, cabe destacar el rico legado de los pastizales de montaña como entidad sociocultural, paisajística y geoecológica, por lo que su gestión merece una profunda reflexión acorde con los tiempos de cambio global que están aconteciendo.

Palabras clave: pastizales; montaña; dinámica de la vegetación; patrimonio; Asturias; Cordillera Cantábrica 
S. Beato; J. L. Marino; M. Á. Poblete; Los pastos de montaña de la Sierra del Aramo (Macizo Central Asturiano):

Resum. Les pastures de muntanya de la Serra de l'Aramo (Massís Central Asturià): anàlisi geoecològica, evolució històrica i dinàmica recent

S'analitzen les pastures montanes i subalpines de la Serra de l'Aramo, bastió calcari del Massís Central Asturià, centrant-se no només en l'estat i la composició dels prats, sinó també en el seu origen i esdevenir històric, especialment en la dinàmica actual. Les metodologies emprades inclouen, entre d'altres, l'estudi florístic i fitosociològic, la cartografia de cobertes vegetals i d'hàbitats d'interès comunitari de port herbaci, l'assaig de la pedoantracologia i tècniques historicistes. Com a resultat, s'han caracteritzat les pastures montanes i subalpines, així com cartografiat la distribució dels hàbitats herbacis 6170, 6210, 6230, 6510, 8130 i 8210 , i ha quedat establerta l'expansió de les pastures durant l'edat del bronze. Així doncs, cal destacar el ric llegat de les pastures de muntanya com a entitat sociocultural, paisatgística i geoecològica, de manera que la seva gestió mereix una profunda reflexió d'acord amb el canvi global actual.

Paraules clau: pastures; muntanya; dinàmica de la vegetació; Astúries; serralada Cantàbrica

\section{Resumé. Les alpages de la Sierra del Aramo (Massif Central Asturien): analyse géoécologique,} évolution historique et dynamique récente

Les prairies montagnardes et subalpines de la Sierra del Aramo, bastion calcaire du Massif Central Asturien, sont analysées en se focalisant non seulement sur l'état et la composition des formations prariales, mais aussi sur leur origine et leur évolution historique, en particulier dans la dynamique actuelle. Les méthodologies utilisées comprennent, entre autres, l'étude floristique et phytosociologique, la cartographie des couvertures végétales et des habitats d'intérêt communautaire de l'herbacée, le test de pédoanthracologie et les techniques historicistes. En conséquence, les pâturages montagnards et subalpins ont été caractérisés, ainsi que la répartition des habitats herbacés 6170, 6210, 6230, 6510, 8130 et 8210 , et on a établi l'expansion des pâturages à l'âge du bronze. Ainsi, il convient de souligner le riche héritage des prairies de montagne en tant qu'entité socioculturelle, paysagère et géo-écologique, de sorte que leur gestion mérite une réflexion approfondie en fonction des temps de changement global en cours.

Mots-clés: prairies; montagnes; dynamique de la végétation; Asturies; Montagnes Cantabriques

Abstract. The mountain pastures of the Sierra del Aramo (Asturian Central Massif): geoecological analysis, historical evolution and recent dynamics

This article analyzes the montane and subalpine grasslands of the Sierra del Aramo, a limestone bastion of the Asturian Central Massif. The study focuses not only on the state and composition of the pasture formations, but also on their origin and historical evolution, especially in the current dynamics. The methodologies used include, among others, a floristic and phytosociological study, the mapping of vegetation covers and herbaceous habitats of community interest, a pedoanthracology analysis and historicist techniques. As a result, montane and subalpine pastures have been characterized, as well as the distribution of herbaceous habitats $6170,6210,6230,6510,8130$ and 8210 , establishing the expansion of these pastures in the Bronze Age. Given the rich legacy of mountain grasslands as a sociocultural landscape and geoecological entity, it is important to reflect deeply on their management in the current scenario of global change.

Keywords: grasslands; mountains; vegetation dynamics; Asturias; Cantabrian Mountains 


\section{Sumario}

$\begin{aligned} \text { 1. Introducción } & \text { 4. Resultados y discusión } \\ \text { 2. Área de estudio } & \text { 5. Conclusiones } \\ \text { 3. Metodología } & \text { Referencias bibliográficas }\end{aligned}$

\section{Introducción}

Además de entidades físicas, las montañas son entidades singularizadas y construidas socialmente a través de un proceso histórico de optimización de los recursos que tuvo como uno de sus resultados la complementariedad entre espacios de pasto en las zonas más elevadas y de cultivo en las bajas (Ortega Valcárcel, 1989; García Fernández, 1990; Fernández, 2006). Este escalonamiento estaba condicionado por múltiples factores geoecológicos propios de la diversidad ambiental montana, así como por el cambio estacional, característico de un clima templado como el oceánico en el norte peninsular, que configuró también los aprovechamientos, las normas, las creencias y las costumbres, teniendo en cuenta los desplazamientos entre las distintas unidades territoriales (Muñoz, 2000; García, 2003; Corbera, 2006; Serrano, 2012; Fernández, 2017). Por tanto, los pastizales forman parte del paisaje de montaña y constituyen un patrimonio dentro de estos complejos sistemas socioculturales (Serrano, 2012; Martínez, 2016).

Los Puertos del Aramo, en referencia explícita al aprovechamiento ganadero montano de la sierra, se sitúan en su plataforma carbonatada, por encima de los $1.300 \mathrm{msnm}$, pero muy por debajo del límite superior del bosque, donde se albergan pastizales desde tiempos inmemoriales con un claro origen antrópico (Beato et al., 2019a). El uso de estos pastos ha sido regulado de forma tradicional, posteriormente legal, a través de ordenanzas locales y sanciones regionales, mucho más si cabe con su categorización como Montes de Utilidad Pública, iniciada en 1859 con la Clasificación General de los Montes Públicos (Real Orden de 30 de septiembre), suscitada por el proceso desamortizador de los años previos (López, 2007; Martínez, 2016). Así, los pastos del Aramo están incluidos en el Catálogo de MUP del Principado de Asturias y, por esto, están sometidos a un régimen jurídico que establece que su tutela corresponde al Gobierno regional y, en este caso, al Servicio de Planificación y Gestión de Montes.

En efecto, los pastos de montaña han constituido tradicionalmente un patrimonio de las comunidades locales que ha desempeñado un papel trascendental en la subsistencia de las aldeas. Por tanto, han sido frecuentes los conflictos sociales entre los ricos y poderosos (congregaciones religiosas, nobles y grandes propietarios) y las pequeñas familias campesinas por el uso de los pastizales montanos, y así está documentado desde el siglo XVI (García Fernández, 1980). Es más, estas disputas se han producido también desde entonces por motivos jurisdiccionales, hasta convertirse en litigios entre los diferentes concejos que hacían uso de este importante recurso (Rodríguez, 1989). No es para menos, 
ya que de la alimentación estival del ganado en los puertos dependía buena parte de la organización económica anual de las familias y, por tanto, su supervivencia. Así, la importancia de este recurso para los pueblos y las aldeas de los concejos de Morcín, Riosa y Quirós principalmente, también de Lena, Proaza y Santo Adriano, ha estado plasmada en las disputas territoriales que todavía hoy continúan (La Nueva España, 20/09/2009; 28/08/2013; 20/02/2018; 02/09/2020; La Voz del Trubia, 18/02/2018; 19/02/2018; 31/07/2018; 03/09/2020), a pesar de los fuertes cambios socioeconómicos de las últimas décadas. Ciertamente, el abandono de las actividades agroganaderas tradicionales ha favorecido la pérdida de un $17,22 \%$ de la superficie dedicada a pastos (Beato et al., 2019b), debido a los procesos de matorralización y reforestación silvestre que tienen lugar desde mediados del siglo pasado. En efecto, el sistema de aprovechamiento ganadero actual está orientado casi por completo a la producción de carne de vacuno, con la minimización en lo posible de los costes productivos. Así, los pastos siguen constituyendo un recurso, pues permiten la alimentación del ganado durante los meses de verano, pero se concentran en los lugares más accesibles mediante vehículos de motor y con disponibilidad de agua. En estos enclaves se introducen elementos de la sociedad más tecnificada y con mayores cambios geoecológicos, mientras que en el resto se activan procesos de abandono y reforestación (González et al., 2018; Beato, 2018).

A pesar de que las formaciones herbáceas cantábricas fueron estudiadas con precisión en el pasado siglo (Mayor et al., 1973; 1977; 1978; Díaz y Fernández, 1994; INDUROT, 1994), las transformaciones mencionadas requieren nuevos análisis, especialmente de escala local. En efecto, su condición de patrimonio, tanto por el hecho de ser producción forrajera como por su catalogación como bien de interés paisajístico y ecológico, hace necesaria una actualización del conocimiento utilizando áreas de estudio concretas (Argamentería, 2004; Remón et al., 2009; Argamentería et al., 2010; González et al., 2018).

En definitiva, los objetivos de este trabajo son tres: $a$ ) analizar el estado de los pastizales montanos del Aramo a partir de su estudio geoecológico y florístico; b) conocer su evolución histórica; c) interpretar su valor patrimonial.

\section{2. Área de estudio}

La Sierra del Aramo forma parte del sector central del Macizo Asturiano en su vertiente septentrional. En concreto, se localiza a $20 \mathrm{~km}$ al SW de Oviedo, donde se prolonga con altitudes por encima de los $1.300 \mathrm{~m}$ con una dirección dominante NNO-SSE a lo largo de unos $15 \mathrm{~km}$ de longitud (figura 1). Presenta una plataforma culminante en la que aflora el roquedo calcáreo desnudo con una superficie muy karstificada plagada de dolinas, con la presencia de varios valles muertos y cumbres en resalte, cuya máxima altitud es $1.791 \mathrm{~m}$ en el pico Gamoniteiro. Las arcillas de descalcificación recubren las depresiones y sirven para el desarrollo de pastos que son sustituidos por otras comunidades herbáceas y de mayor porte allí donde domina la roca. De la zona cacuminal parten pindias pendientes con escarpes, superficies regularizadas, canchales y 
Los pastos de montaña de la Sierra del Aramo (Macizo Central Asturiano): S. Beato; J. L. Marino; M. Á. Poblete; análisis geoecológico, evolución histórica y dinámica reciente

R. Cunill; J. M. Rodríguez

Figura 1. Localización del área de estudio

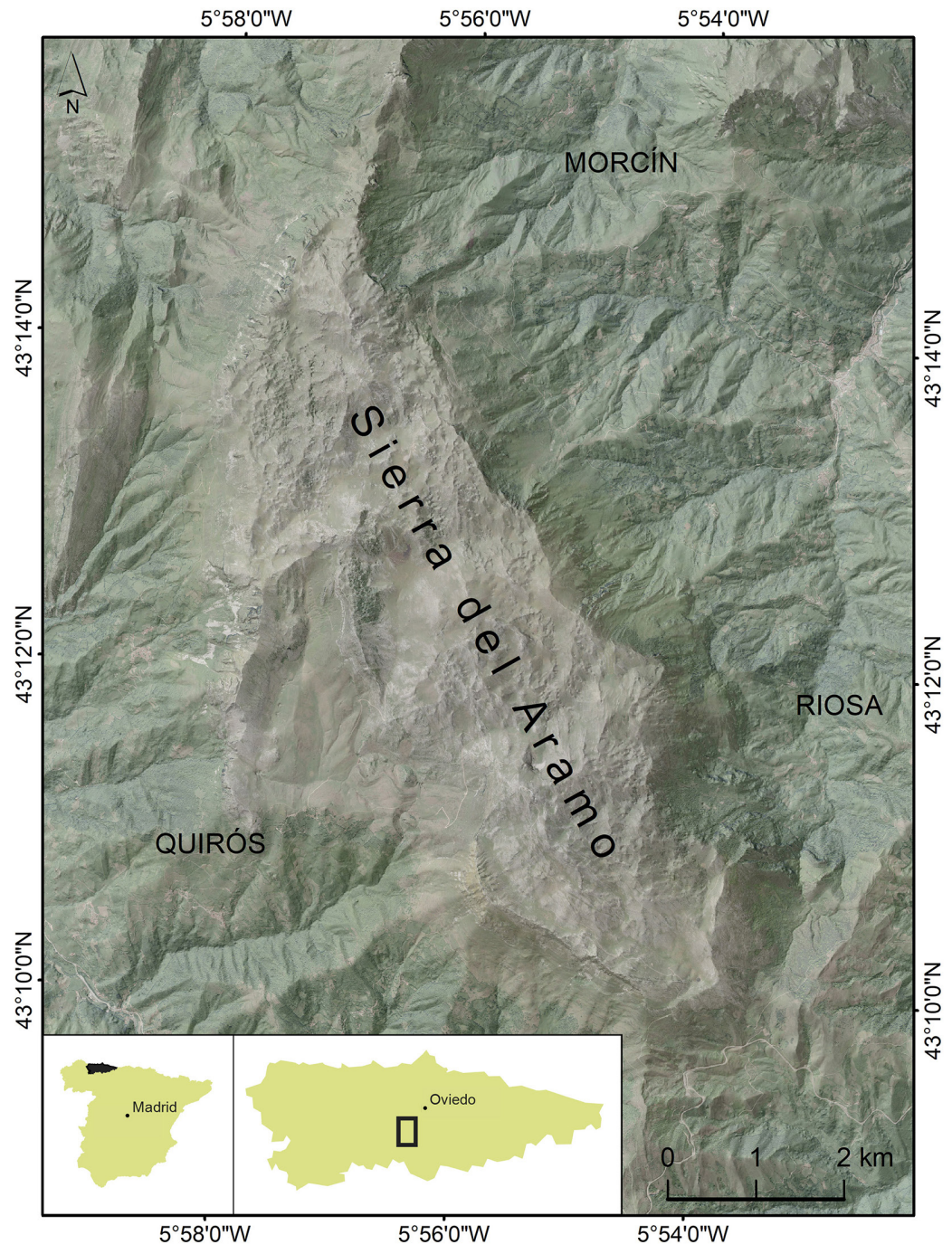

Fuente: elaboración propia.

depósitos de grandes movimientos en masa, recubiertos también por pastizales, si bien estos conviven con extensas manchas arbustivas y bosques.

La Sierra del Aramo tiene un clima propio del dominio atlántico típico. El piso montano presenta temperaturas medias entre los $10,9^{\circ} \mathrm{C}$ y los $6,6^{\circ} \mathrm{C}$. No obstante, Muñoz (1982) estima que las temperaturas medias en esta franja pueden encontrarse entre los $9,44^{\circ} \mathrm{C}$ a los $800 \mathrm{~m}$ de altitud y los $4,94^{\circ} \mathrm{C}$ de 
los $1.600 \mathrm{~m}$. Según dicho autor, por encima de dicha cota las medias descenderían hasta los $4,38^{\circ} \mathrm{C}$ a $1.700 \mathrm{~m}$ y los $3,82^{\circ} \mathrm{C}$ en las cumbres. En cuanto a las temperaturas medias de las mínimas, están entre los $7^{\circ} \mathrm{C}$ (incluso 8 o $9^{\circ} \mathrm{C}$ en el sector más noroccidental — valle del Trubia, Las Xanas-) y los $2^{\circ} \mathrm{C}$ de las zonas elevadas. Por otro lado, los datos extremos indican unas temperaturas medias mensuales de mínimas absolutas por debajo de $-4^{\circ} \mathrm{C}$ entre diciembre y marzo y por debajo de los $0^{\circ} \mathrm{C}$ desde septiembre a junio, en una cota media. Por encima de los $1.500 \mathrm{msnm}$ se encuentran las cifras más extremas, con mínimas en enero $\left(-11,3^{\circ} \mathrm{C}\right)$ y febrero $\left(-12,2^{\circ} \mathrm{C}\right)$. Así, en estas áreas se trata de un clima propiamente frío o de alta montaña, caracterizado por tres a seis meses con temperaturas por debajo de $0{ }^{\circ} \mathrm{C}$ y con buena parte de las precipitaciones en forma de nieve (Muñoz, 1982). En función de la información de la estación meteorológica de Leitariegos $(1.530 \mathrm{msnm})$, la temperatura media mensual de las mínimas absolutas está por debajo de $0^{\circ} \mathrm{C}$ en 10 meses al año, y pueden haber heladas y llegar a los $10^{\circ} \mathrm{C}$ negativos desde diciembre a abril. Estos valores dan buena cuenta de las rigurosidades del clima en el área cacuminal de la Sierra del Aramo (Beato, 2018).

Así, se pueden distinguir varios pisos bioclimáticos, con cubiertas vegetales específicas, en función de los cambios en altitud de los valores termoclimáticos y ombroclimáticos. A partir de los $700 \mathrm{msnm}$ esta unidad montana presenta climas de tipo fresco (Cfsc) y frío (Dfsc). En cuanto a las temperaturas, por encima de la franja colina hay dos termotipos determinados, que, a partir del índice de termicidad, son: el supratemplado (montano) y el orotemplado (subalpino). En lo que respecta a la humedad, la Sierra del Aramo presenta tres ombrotipos diferenciados (sin descartar un cuarto ultrahiperhúmedo por la falta de datos locales), los cuales son, en los pisos montano y subalpino y según las variables establecidas por Díaz y Fernández (1994, 2006) y RivasMartínez (2005): húmedo e hiperhúmedo. Estas diferencias climáticas, junto a las topográficas y edáficas, explican en buena medida la presencia de varias series, geopermaseries y tipos de vegetación potencial.

Efectivamente, la Sierra del Aramo configura una bisagra biogeográfica entre las subprovincias cantabro-atlántica y orocantábrica dentro de la provincia atlántico-europea de la región eurosiberiana (Beato et. al, 2017). En concreto, esto supone diferencias orográficas, ombrotérmicas y de continentalidad relevantes que se plasman en la actividad biológica. Así, según el mapa de vegetación de series, geoseries y geopermaseries de Asturias a escala 1:250.000 (Díaz, 2014) y la caracterización de los distritos biogeográficos del Principado de Asturias de Díaz (2009), en el Aramo y sus estribaciones figuran las siguientes formaciones de vegetación potencial como cabecera o etapa clímax: carbayedas eutrofas con arces y fresnos (Polysticho setiferi-Fraxinetum excelsioris), encinares cantábricos (Lauro nobilis-Quercetum ilicis), saucedas blancas arborescentes (Salicetum angustifolio-albae), carbayedas oligotrofas con abedules (Blechno spicant-Quercetum roboris), alisedas ribereñas orientales (Hyperico androsaemi-Alnetum glutinosae), hayedos eutrofos con mercurial (Carici sylvaticae-Fagetum sylvaticae), carrascales cantábricos (Cephalanthero 
longifoliae-Quercetum rotundifoliae), enebrales rastreros subalpinos calcáreos (Daphno cantabricae-Arctostaphylo uvae-ursi), tiledas o tilares orocantábricos con robles albares y fresnos (Helleboro occidentalis-Tilietum platyphyllii), rebollares orocantábricos (Linario triornithophorae-Quercetum pyrenaicae), hayedos orocantábricos oligótrofos con abedul (Blechno spicanti-Fagetum sylvaticae), abedulares orocantábricos (Luzulo henriquesii-Betuletum celtibericae), robledales albares de umbrías con abedules (Luzulo henriquesii-Quercetum petraeae), acebedas orocantábricas e ibéricas (Saniculo europaeae-Ilicetum aquifolii) y fresnedas ribereñas orocantábricas (Festuco giganteae-Fraxinetum excelsioris). No obstante, la intensa antropización secular del territorio generó amplias superficies de pastizal y modificó la estructura y la extensión de todas las formaciones vegetales. Recientemente, el fin del sistema de explotación tradicional y el despoblamiento del medio rural provocaron el abandono de prados y pastos y el crecimiento de las áreas arbustivas y forestales (Beato et. al, 2016, 2019b).

\section{Metodología}

Para alcanzar los objetivos planteados en esta investigación, se han obtenido resultados de varios métodos y técnicas. En primer lugar, se ha realizado una exhaustiva revisión bibliográfica y se han efectuado inventarios aleatorios para la caracterización de las formaciones vegetales herbáceas consultando los trabajos previos específicos del Aramo de Navarro (1974a; 1974b) y Beato (2018). Con las herborizaciones se ha tratado de conocer la composición florística y la estructura fisonómica en las zonas de muestreo, así como interpretarlas según criterios fitosociológicos de abundancia-dominancia de la especie (Braun-Blanquet, 1979; Fidalgo, 1997; Arozena y Molina, 2000). Sirvieron, obviamente, para la realización de cartografía biogeográfica de gran utilidad para la gestión territorial (Bertrand, 1966; Panareda, 1996). En concreto, en este trabajo se presenta un mapa de pastos elaborado a escala 1:25.000 partiendo de la información contenida en el Mapa Temático de Vegetación del Principado de Asturias (INDUROT, 1994), el Mapa Forestal de España del Cuarto Inventario Forestal Nacional (edición digital actualizada: MAPAMA, 2018) y el mapa de vegetación de Beato (2018), utilizando como unidades de clasificación los hábitats herbáceos de interés comunitario para la UE. Así, se han corregido y precisado los límites espaciales de los diferentes elementos que constituyen el mosaico herbáceo mediante la fotointerpretación del ortofotomapa del PNOA de 2017 y el software informático Arcgis 10.1. Además, se ha efectuado la fotointerpretación de imágenes aéreas — vuelo americano 1956-57, vuelo interministerial 1973-1986, vuelo nacional 1980-1986 y vuelo del PNOA 2014- y de fotografías de paisaje teniendo en cuenta la información aportada por miembros de instituciones de comunidades locales y lugareños, que han contribuido a la interpretación del patrimonio cultural y a la valoración de la dinámica reciente de las formaciones vegetales a tenor de los cambios socioeconómicos.

Por otra parte, para averiguar el origen de los pastos de la Sierra del Aramo se realizaron dos sondeos pedoantracológicos por encima del límite del bosque 
actual, en el marco del proyecto «Dinámica paleoecológica del Macizo Central Asturiano a través de un transecto pedoantrocológico", que ya ha dado lugar a una publicación (Beato et al., 2019a). En concreto, se trata de dos fosas a 1.701 (ARAMO 1) y a $1.611 \mathrm{msnm}$ (ARAMO 2) en dos depósitos de arcillas de descalcificación en depresiones kársticas cubiertas por el pasto. El método pedoantracológico consiste en excavar una zanja hasta alcanzar la roca madre para la extracción de muestras completas de suelo de entre 5 y $10 \mathrm{~kg}$ por nivel (Cunill, 2010; Cunill et al., 2012, 2013). Una vez secadas y pesadas las muestras, son tamizadas en húmedo con tamices de $5 \mathrm{~mm}, 2 \mathrm{~mm}$ y $0,8 \mathrm{~mm}$ de luces de malla. Con la ayuda de una lupa binocular, se obtienen los fragmentos de carbón. El conocimiento de las especies leñosas de las que procede el carbón se efectúa mediante identificación anatómica de la madera a través de un microscopio y con la ayuda de los atlas de anatomía de la madera (Schweingrüber, 1990a, 1990b; Vernet et al., 2001) y colecciones de referencia. Finalmente, la datación por carbono 14 (AMS radiocarbono) de los fragmentos de carbón nos permite fechar la existencia de formaciones vegetales leñosas en las áreas actualmente deforestadas y cubiertas por pastos. Se realizaron siete dataciones de fragmentos de carbón en el Poznań Radiocarbon Laboratory (Polonia), que posteriormente se han calibrado utilizando el programa OXCAL 4.3 (Bronk, 2017) y la curva de calibración IntCal13 (Reimer et al., 2013).

\section{Resultados y discusión}

\subsection{Caracterización biogeográfica}

La riqueza de los pastizales del Aramo depende de las condiciones meteorológicas anuales, toda vez que el volumen total de precipitaciones, tanto en estado líquido como sólido, puede variar bastante de un año para otro, incluso la evapotranspiración. Así, se producen sequías en las que la producción de forrajes es menor y de peor calidad, y grandes nevadas tardías que retrasan el desarrollo de muchas especies vegetales y acortan su periodo vegetativo y la productividad de los pastos. Se trata, en todo caso, de formaciones herbáceas originadas en buena medida por la actividad antrópica (salvo algunas comunidades climácicas subalpinas y rupícolas), pues nos encontramos por debajo del límite superior actual del bosque. En efecto, la plataforma culminante del Aramo está salpicada de pastos que conviven con afloramientos rocosos y gleras, en los cuales aparecen parches diferenciados debido a una intensidad mayor o menor en los usos y, por supuesto, al diferente grado de profundidad y permeabilidad del suelo. En definitiva, es muy difícil establecer límites netos entre formaciones vegetales herbáceas, mucho más si cabe, establecer asociaciones fitosociológicas puras (Mayor et al., 1973).

A tenor de los trabajos realizados hasta la fecha en los pastos cantábricos (Mayor et al., 1973, 1977, 1978; Díaz y Fernández, 1994; INDUROT, 1994), se presuponen para la Sierra del Aramo las clases Molino-Arrhenatheretea (pastos comunes de diente cantábricos), Festuco hystricis-Ononidetea striatae 
(céspedes psicroxerófilos), Festuco-Brometea (formaciones herbáceas subalpinas) y Nardietea strictae (formaciones herbáceas densas y acidófilas). Navarro (1974a, 1974b), en el estudio botánico más preciso realizado sobre el Aramo, indicaba igualmente estas clases y explicaba que se trataba de un mosaico muy fragmentado y heterogéneo debido a los diferentes tipos de suelo, al contacto entre comunidades vegetales diversas y, especialmente, a unas actividades agroganaderas con raíces muy antiguas (Beato, 2018).

Las formaciones herbáceas manejadas por siega o diente eran una de las cubiertas vegetales de mayor extensión en las laderas y los valles basales del Aramo e incluso en los pisos superiores en tiempos de escasez. Una vez cesada la actividad agroganadera, el monte y el bosque han crecido a su costa. Anteriormente, hasta mediados del siglo XX, muchos de estos prados fueron, además, espacios cultivados con escanda, maíz y patatas, lo que otorgaba al paisaje una mayor variedad cromática (incluso tenemos testimonios de parcelas sembradas de patatas en algunas majadas por encima de los $1.500 \mathrm{msnm}$ ).

Las superficies pratenses de este tipo presentan numerosas especies de gramíneas, herbáceas y leguminosas. Sin embargo, están dominadas en la actualidad por algunas especies forrajeras como el vallico (Lolium perenne, Lolium multiflorum) y prima la monoespecificidad. No obstante, todavía persisten algunos prados florísticamente más variados y con especies propias o naturalizadas. Así, en los análisis botánico-socioecológicos de Navarro (1974a) y Mayor (1996), en la Sierra del Aramo se mencionan los siguientes tipos de prados:

- Praderas colinas de Linum bienne y Cynosurus cristatus con Gaudinia fragilis, Lolium perenne y Trifolium squamosum.

- Prados mesófilos sobre suelos húmedos eutrofos en la transición del piso colino al montano dominados por Malva moschata y Arrhenatherum elatius subsp. bulbosum con Tragopogon pratensis, Sanguisorba minor y Galium verum.

- Pastos sobre suelos secos eutrofos y esqueléticos del piso colino de Saxifraga tridactylites, Minuartia hybrida, Euphorbia exigua, Linum strictum y Ononis reclinata.

- Céspedes colinos húmedos y nitrófilos de zonas alteradas caracterizadas por Lolium perenne, Plantago major, Polygonum aviculare, Poa annua, Potentilla reptans, Coronopus dydimus y Verbena officinalis.

Especialmente importantes en las vertientes solanas son los prados montanos de la asociación Malvo moschatae-Arrhenatheretum bulbosi, que suben por encima de los 600-700 msnm, hasta sobrepasar los 1.100 en algunas laderas quirosanas. Pese a la altitud, no dejan de ser prados de siega florísticamente variados y diversos de una gran riqueza, además, paisajística. A esto contribuyen también los cierres vegetales de las fincas, fundamentales para el mantenimiento de la biodiversidad tanto vegetal como animal, pues sirven de corredores y como reservorios de especies arbustivas y arbóreas autóctonas, a pesar de que se han introducido especies de jardinería en algunas áreas más cercanas a 
las aldeas. También se emplean plantas de porte arbóreo en las sebes: fresnos, carbayos y castaños, e incluso rebollos, abedules y acebos, donde abundan plantas trepadoras y otras relacionadas con la actividad antrópica.

Por otro lado, se distinguen distintos tipos de formaciones herbáceas a partir de los 1.000-1.100 msnm, tales como pastos (mesófilos e higrófilos), lastonares, cervunales o nardetas (en las laderas, las morteras y los Puertos del Aramo), así como pastizales y céspedes psicroxerófilos calcícolas en la plataforma culminante. Al igual que los prados, todos ellos han dependido también de la continuidad de su manejo pastoril e incluso de la siega en algunos casos. No obstante, lastonares calcícolas, cervunales y céspedes se consideran formaciones herbáceas no pratenses que pueden constituir comunidades permanentes de ambientes rupícolas calcáreos, de suelos con solifluxión, gelifluxión u otros procesos geomorfológicos que impiden la estabilidad en el piso montano, además de zonas de innivación prolongada del piso subalpino. La presencia en los pastos culminantes de escuernacabras, mostajos, serbales, fresnos y tejos aislados denota la vegetación potencial de porte arbóreo en esta área, al igual que hayas y robles en las laderas.

En general, los pastizales están formados por diversas gramíneas, compuestas y leguminosas que generan conjuntos densos, salvo los céspedes, discontinuos y abiertos. A menor altitud sirven de cobijo y alimento al ganado durante la primavera y el otoño, mientras que la utilización de los pastos de la plataforma calcárea superior se abre al ganado mayor en el mes de junio. Por otro lado, allí donde las condiciones edáficas están condicionadas por la presencia de agua en el suelo buena parte del año, se desarrolla vegetación higrófila sobre un anmoor ácido (Carex sp. pl., Juncus sp. pl.). Las especies más significativas son Senecio aquaticus, Juncus acutiflorus, Crepis paludosa, Myosotis lamottiana, Caltha palustris, Filipendula ulmaria, etcétera. Además, en los suelos nitrificados de los pastizales de uso más intenso crecen especies vegetales comunes de espacios antropizados, como las ortigas (Urtica dioica) y las zarzas (Rubus sp. pl.).

Según los trabajos de Navarro (1974a) y Mayor (1996), en la Sierra del Aramo se encuentran los siguientes tipos de pastizal montanos y subalpinos:

- Comunidades pioneras de Rumex scutatus y Pritzelago alpina subsp. auerswaldii que colonizan pedregales del piso montano con Arabis alpina, Vincetoxicum hirundinaria y Digitalis parviflora.

- Pastizales calizos discontinuos sobre suelos esqueléticos cacuminales con sequedad estival dominados por Festuca burnatii y Erodium glandulosum con Carex sempervirens, Helianthemum croceum subsp. cantabricum, Saxifraga conifera, Globularia repens, Minuartia verna, Sedum atratum, Poa alpina y Sesleria caerulea.

- Pastizales mesófilos sobre suelos profundos por encima de los $1.200 \mathrm{~m}$ caracterizados por Bromus erectus, Helianthemum nummularium, Brachypodium pinnatum subsp. rupestris, Euphorvia flavicoma subsp. occidentalis, Hippocrepis comosa, Koeleria vallesiana, etcétera. 
- Cervunales de suelos montanos descarbonatados, por encima de los $1.200 \mathrm{~m}$, de Nardus stricta y Galium saxatile con Polygala vulgaris, Polygala serpyllifolia, Serratula tinctoria, Potentilla erecta y Plantago alpina.

- Herbazales nitrófilos de alta montaña alterada por el ganado. Son características: Chenopodium bonus-henricus, Senecio duriaei, Astragalus depressus, Lamium album, Anthriscus caucalis, Geranium dissectum, Urtica dioica y Malva sylvestris.

Aunque nuestros inventarios pueden corroborar en buena medida estos datos y ajustarse a las clasificaciones fitosociológicas establecidas para la Sierra del Aramo, debemos realizar algunas apreciaciones:

- Por un lado, la presencia de algunos taxones en casi todos los inventarios, ya fuesen realizados en roquedos calizos como en depresiones colmatadas de arcillas. Es el caso, por ejemplo, de Carex brevicollis, herbácea perenne que se ve favorecida porque al ganado no le interesa. Estas matas cespitosas propias de ambientes edáficos alcalinos comparten protagonismo con Chamaespartium sagittale, que, por el contrario, se asocia a suelos más bien ácidos (figura 2). Otras sufruticosas con una amplia presencia en los pastos del Aramo son Helianthemum canum y Helianthemum nummularium, incluso en comunidades rupícolas y de suelos esqueléticos.

Figura 2. Pastos de la plataforma culminante con abundancia de Carex brevicollis y Chamaespartium sagittale entre la vegetación casmófita y arbustiva de los roquedos

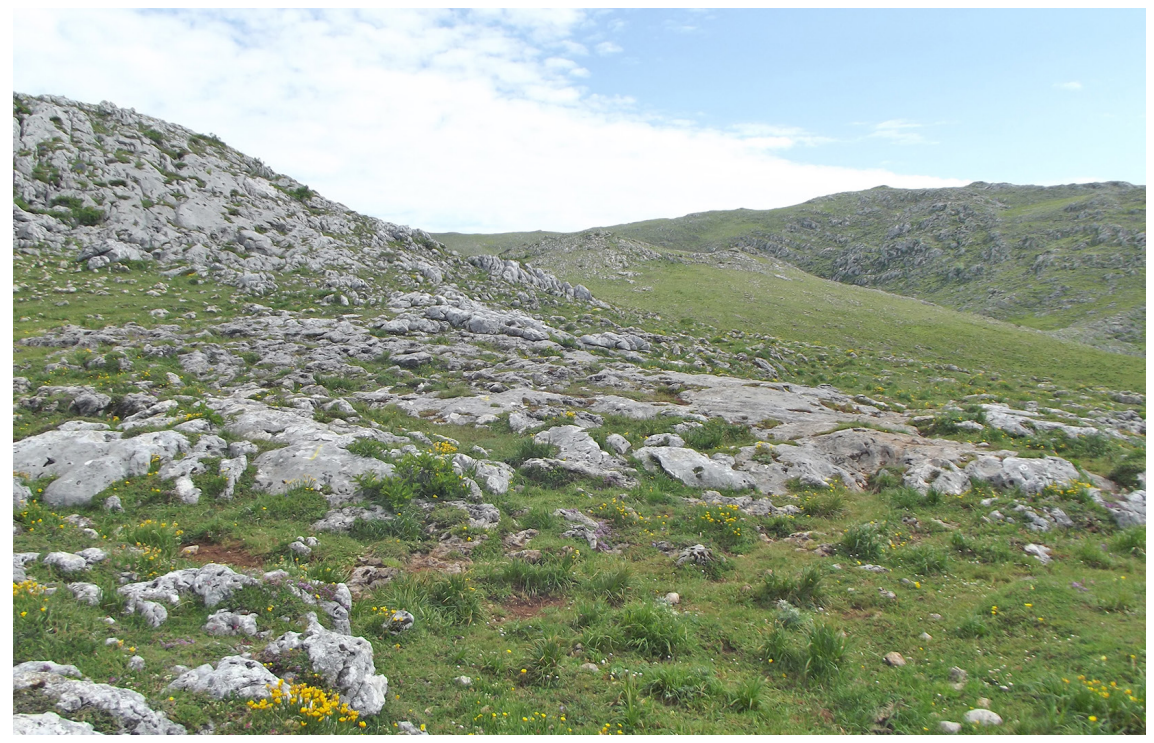

Fuente: elaboración propia. 
- En los pastos subalpinos, son comunes (además de las mencionadas) Festuca burnatii, Bromus erectus, Carex sempervirens, Helianthemum croceum subsp. cantabricum, Saxifraga canaliculata, Saxifraga trifurcata, Veratrum album, Sesleria albicans, Saxifraga granulata, Cerastium arvense, Alchemilla catalaunica, Dianthus hyssopifolius, Vicia pirenaica, etcétera, acompañadas de algunas leñosas como Juniperus alpina, Genista hispanica subsp. occidentalis y Berberis vulgaris subsp. cantabrica.

- En los pastos montanos, igualmente con la presencia de Helianthemum y Carex, destacan Anthyllis vulneraria, Bellis perennis, Cerastium arvense, Eryngium bourgatii, Euphorbia flavicoma, Festuca rubra, Galium verum, Hippocrepis comosa, Koeleria vallesiana, Linaria supina subsp. supina, Lotus corniculatus, Plantago lanceolata, Plantago media, Potentilla erecta, Sanguisorba minor, Teucrium pyrenaicum, Thymus praecox y Trifolium repens.

- Los taxones acidófilos aparecen en múltiples céspedes altimontanos, por ejemplo, Jasione laevis, Carex pilulifera, Hypochoeris radicata y Potentilla erecta. En ningún caso se ha detectado Nardus stricta.

En todo caso, cabe destacar que, pese a la homogeneización general del mosaico pratense, en la Sierra del Aramo permanece una variada muestra de pastos montanos debido a la diversidad de situaciones geoecológicas que alberga. No obstante, la concentración del ganado en algunos enclaves está favoreciendo la extensión en estas zonas y sus adyacentes de plantas asociadas a los usos antrópicos (suelos ruderales y nitrificados) e incluso la destrucción del tapiz herbáceo.

\subsection{Cartografia y hábitats de interés comunitario de porte herbáceo}

La realización de mapas en lugares donde están presentes varias formaciones vegetales pratenses es muy complicada debido a las dificultades para fotointerpretarlas, pues fisionómicamente y utilizando las escalas cartográficas habituales es imposible delimitarlas. A no ser que, sobre el terreno, efectuando constantemente inventarios y con un GPS, se proceda a la delimitación, cuestión prácticamente inabordable en áreas de estudio extensas. Por esto, las referencias cartográficas de las que disponemos se basan en conocimientos regionales conjugados con análisis de las condiciones topográficas y edáficas locales (altitud, orientación, tipos de suelos y roquedos), a fin de cuentas, en cuestiones más o menos generales. Así, el mapa de vegetación de la cartografía temática ambiental del Principado de Asturias a escala 1:25.000 (INDUROT, 1994) muestra una Sierra del Aramo que alberga, fundamentalmente, céspedes psicroxerófilos de la asociación Festucetum burnatii, en la que destacan, según su memoria, Festuca burnatii, Festuca hystrix, Arenaria aggregata ssp. cantabrica y Koeleria vallesiana, entre otras. Esta gran extensión difiere de los estudios de Navarro (1974a; 1974b), que daba un papel mucho más secundario a la asociación. A tenor de nuestros inventarios, corroboramos que el mosaico herbáceo-arbustivo es mucho más complejo de lo que muestra el mapa temático asturiano. 
En dicha cartografía se señalan, igualmente, Merendero pyrenaicae-Cynosuretum cristati, caracterizada por Cynosurus cristatus, Lolium perenne, Agrostis, tenuis y Festuca rubra sobre suelos más desarrollados, así como Bromo erecti-Caricetum brevicollis con Brachypodium pinnatum ssp. rupestre, Bromus erectus y Carex brevicollis en algunas pequeñas manchas dispersas.

Por otro lado, los mapas de vegetación de Beato (2018), que identifica pastos de forma genérica, y el MAPAMA (2018) ofrecen mucha menor precisión, y describen grandes teselas de formaciones arbustivas y herbáceas (figura 3).

Figura 3. Cubiertas de porte herbáceo de la Sierra del Aramo

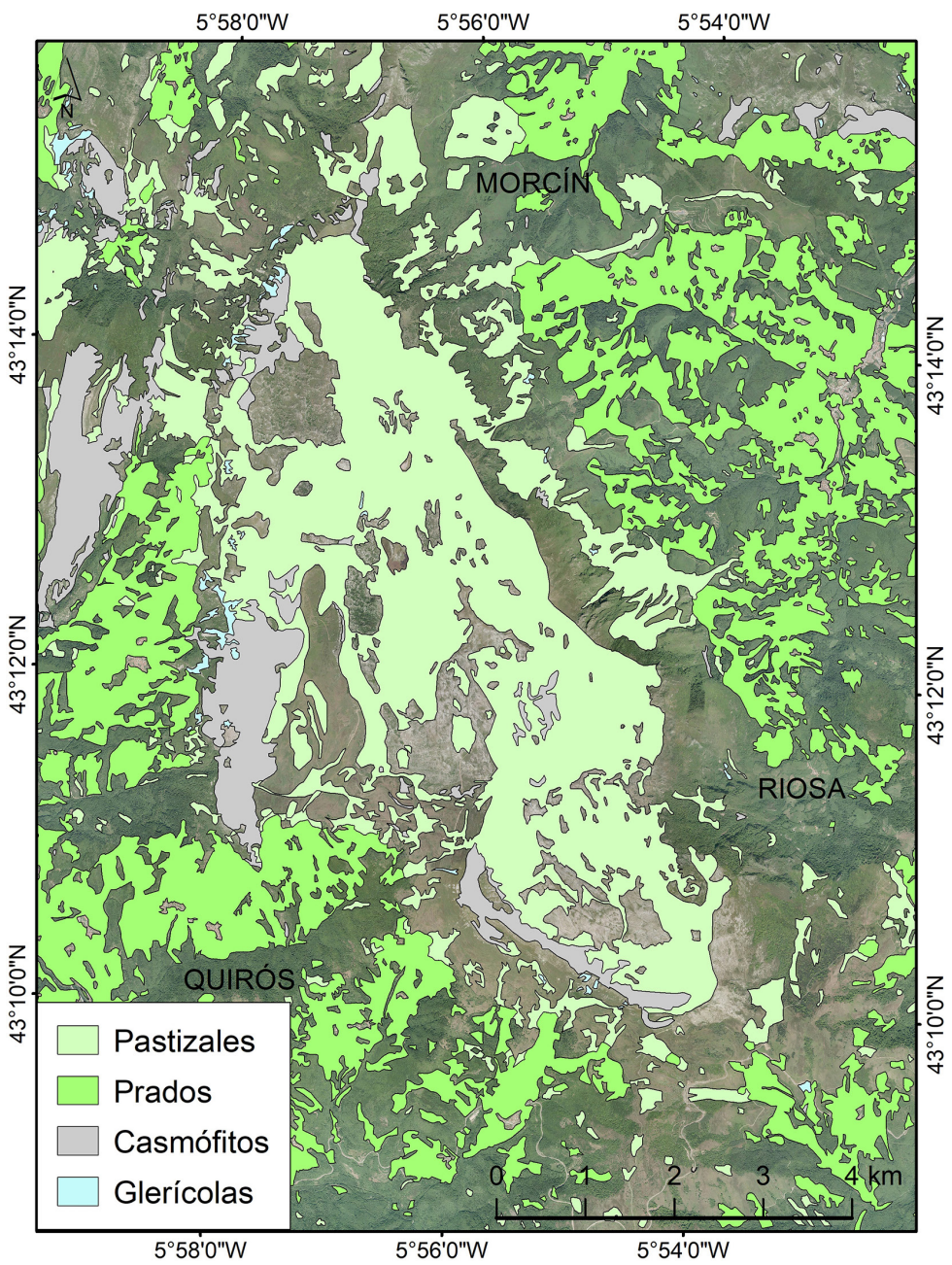

Fuente: modificado de Beato (2018). 
En concreto, el Banco de Datos de la Naturaleza, que alberga la información del Inventario Español del Patrimonio Natural y de la Biodiversidad de acuerdo con la Ley 42/2007, contiene la cartografía del Mapa Forestal de España (MFE) de máxima actualidad, con nueva información provincial generada a escala 1:25.000. Aunque incluye resultados muy valiosos, presenta carencias normales en este tipo de análisis tan amplios (Marino et al., 2017). Por su parte, el mapa digital de hábitats de interés comunitario delimita una plataforma culminante cubierta prácticamente en su totalidad por Daphno cantabricaeArctostaphyletum uvae-ursi, con algunas comunidades de Polygalo edmundiiNardetum en los fondos de algunos valles muertos. En definitiva, la cartografía no aporta un conocimiento exhaustivo de los pastos del Aramo, toda vez que el objeto del análisis y la delimitación es una composición muy fraccionada y diversa. Por tanto, la aplicación de la Directiva Hábitats en España presenta la grave deficiencia de sustentarse en una cartografía imprecisa e incorrecta que es de consulta obligada en los procedimientos de ordenación territorial (Beato et al., 2017). Para tratar de solventar esta carencia, se ha elaborado un mapa a una escala mínima 1:25.000 reconociendo y caracterizando los hábitats de interés comunitario herbáceos y casmofíticos desde el punto de vista biogeográfico y conforme al Manual de Interpretación de los Hábitats de la Unión Europea y documentos específicos de diversos autores (Rivas-Martínez et al., 2003; VV.AA., 2009). El resultado ha sido la localización y el registro cartográfico de los códigos 6170, 6210, 6230 y 6510 (pastos carbonatados, cervunales, céspedes psicroxerófilos, pastos vivaces y prados mesófilos, respectivamente), así como del 8130 y el 8210 (cubiertas discontinuas de agrupaciones glerícolas y casmófitas).

Los pastos de alta montaña caliza (6170) se reducen a algunos parches herbáceos con una suma de 12,32 ha por encima de los 1.600-1.700 msnm. Son pastizales de carácter mesófilo o xeromesófilo de escasa pendiente e inestabilidad, donde se desarrolla la alianza Festucion burnatii (Navarro, 1974a; Mayor, 1996; Remón et al., 2009). Por su parte, los pastos vivaces de Festuco-Brometea (6210) son los propios de sustratos calcáreos en los que progresa una cubierta densa y diversa florísticamente elevada, caracteriza por el orden Brometalia (Yera y Ascaso, 2009) y en el Aramo por la alianza Bromion erecti, subalianza Potentillo-Brachypodienion rupestris (Mayor, 1996). Calculamos unas 696,12 ha de extensión para este código. En cuanto a las formaciones herbosas con Nardus (6230), propias de sustratos silíceos de zonas montañosas o de áreas calcáreas con fuerte lixiviación (Remón et al., 2009), se atribuyen a la alianza Violion caninae. A este respecto, se ha identificado en el Aramo la asociación Serratulo tinctoriae-Nardetum (Navarro, 1974a; Mayor, 1996) y se ha procedido a cartografiar como tal 329,18 ha que se corresponden con amplios enclaves deprimidos rellenos de arcillas de descalcificación (figura 4).

Los prados de siega de montaña (6510) de Arrhenatherion crecen sobre suelos alcalinos y profundos principalmente y son diversos en taxones (Reiné, 2009). En el Aramo hallamos los prados caracterizados por la asociación Malvo 
Figura 4. Mapa de hábitats de interés comunitario de porte herbáceo del Aramo

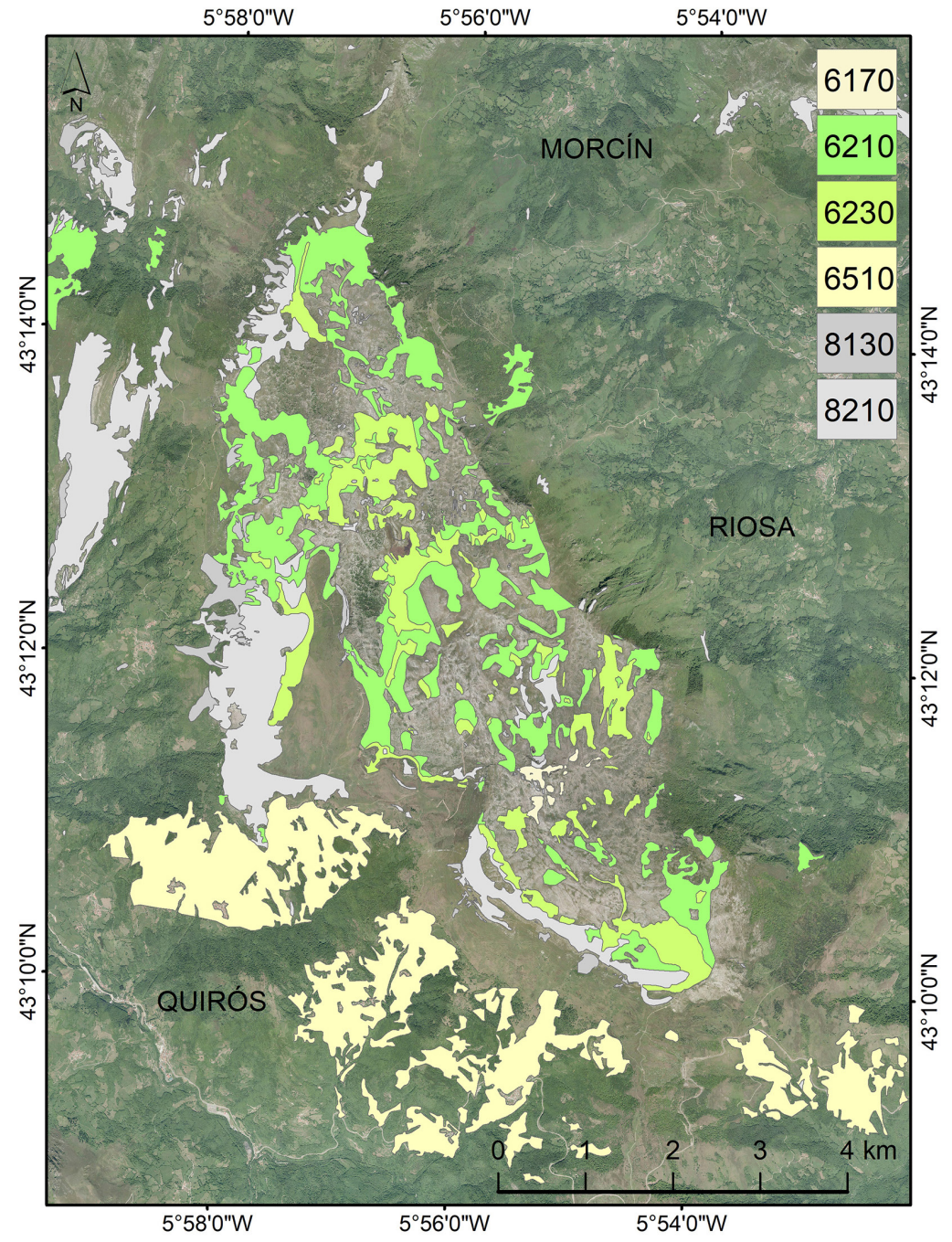

Fuente: elaboración propia.

moschatae-Arrhenatheretum bulbosi por encima de los $1.100 \mathrm{msnm}$ en algunas laderas solanas septentrionales. Como mencionábamos en el epígrafe anterior, al cubrir unas 691,57 ha, constituyen un patrimonio ecológico y paisajístico de alto valor por los usos tradicionales y su configuración estética con sebes y muros de piedra.

Por otra parte, encuadramos dentro de la vegetación de porte herbáceo desprendimientos rocosos occidentales y termófilos (8130) que se presentan 
de manera dispersa sobre una superficie de 185,23 ha configurada por canchales y pedreras. De los taxones que representan la alianza Linarion filicaulis en la Sierra del Aramo, encontramos, por ejemplo, Arabis alpina, Hutchinsia alpina subsp. auerswaldi y Rumex scutatus. Finalmente, los taxones correspondientes a las pendientes rocosas calcícolas con vegetación casmofítica (8210) cubren rupícolamente vastas áreas de afloramientos rocosos. Se trata de la alianza Saxifragion trifurcato-canaliculatae, en concreto, comunidades vegetales de gran valor ecológico y alta endemicidad de la asociación CrepidoErinetum. Así, son frecuentes Erinus alpinus, Crepis albida subsp. asturica, Saxifraga canaliculata, Saxifraga trifurcata, Campanula arvatica subsp. arvatica, Anemone baldensis subsp. pavoniana, Asplenium ruta-muraria y Asplenium trichomanes.

Por último, cabe realizar una reflexión ante la situación de cambio global. En efecto, se está produciendo una importante extensión del matorral y de formaciones arboladas (Beato et al., 2019b) debido al cese de las actividades tradicionales (control mediante el fuego, uso de plantas leñosas en las aldeas, desbroces y siegas, mayor carga ganadera, ganado variado con distintos gustos alimenticios), los nuevos usos antrópicos, los cambios en los elementos del clima y su relación con el modelado del relieve y la distribución de los seres vivos. Así pues, estamos asistiendo a una transformación del mosaico vegetal y paisajístico, y con toda seguridad también de la biodiversidad. Buena parte de las formaciones vegetales arbustivas y arbóreas de la Sierra del Aramo constituyen hábitats de interés comunitario (Beato et al., 2016; Poblete et al., 2020). En este sentido, no es descabellado pensar que si la sucesión vegetal avanza se perderá superficie de hábitats herbáceos, pero se ganarán áreas cubiertas por leñosas igualmente valiosas para los sistemas ecológicos y como patrimonio.

\subsection{Origen de los pastos}

La Sierra del Aramo tiene su cima en el Gamoniteiro, a $1.791 \mathrm{msnm}$. Buena parte de su plataforma culminante karstificada se encuentra entre los 1.400 y los $1.600 \mathrm{msnm}$, esto es, por debajo del límite superior del bosque actual, mucho más en los periodos climáticos holocenos más cálidos. Parece obvio, por tanto, que el dominio de las cubiertas herbáceas no tiene en su origen una explicación en la que no intervengan los seres humanos (Beato, 2018).

Las evidencias arqueológicas en la Cordillera Cantábrica muestran que los modos de vida cazadores-recolectores del Mesolítico se mantuvieron durante más tiempo que en otras zonas de la península Ibérica, seguramente por la disponibilidad de recursos silvestres (Arias, 1991). La colonización de los espacios de media y alta montaña con fines pastoriles se sitúa en torno al cuarto milenio a. C. con la aparición de signos de deforestación (aumento de arbustivas en los registros paleoecológicos), del megalitismo y de asentamientos al aire libre (Blas, 2012, 2013; Cubas et al., 2016). Esta apropiación de los espacios de montaña septentrionales, favorecida por la benignidad 
climática, tuvo su culmen en la Edad del Bronce (Cunill, 2010; Blas, 2012; Pérez-Obiol et al., 2016).

Así lo muestran los resultados pedoantracológicos de los sondeos realizados en esta unidad montana (Beato et al., 2019a). Tanto en ARAMO 1 como en ARAMO 2, se rescataron numerosos fragmentos de carbón procedente de la quema de especies arbustivas y potencialmente arbóreas, a pesar de estar realizados en zonas absolutamente deforestadas, dominadas por cubiertas herbáceas y donde únicamente se desarrollan algunas plantas leñosas aisladas en los afloramientos rocosos que rodean las depresiones colmatadas de arcillas de descalcificación. En concreto, en ARAMO 1 (1.701 msnm) se excavó en una dolina colmatada de la cara sur del Gamoniteiro, cubierta por un pastizal subalpino moderadamente acidificado con algunas matas dispersas de Daphne laureola en los roquedos circundantes. El análisis edáfico mostró unas características del suelo correspondientes a una formación de tipo eutrudept sobre un depósito arcilloso de profundidad desconocida que se perforó hasta los $160 \mathrm{~cm}$ para extraer más de $34 \mathrm{~kg}$ (en seco) de muestras de tierra. Se hallaron 0,7947 gramos de carbón fundamentalmente, piezas milimétricas, ramitas en casi todos los casos de angiospermas (158 fragmentos) muy vitrificadas que no pudieron ser identificadas. Sí pudieron ser identificadas 12 de Ericaceae y, lo más relevante, 4 de Ilex, 3 de Taxus baccata, 3 de Juniperus alpina, 3 de Fagus y 2 de Corylus.

El sondeo ARAMO 2 (1.611 msnm) se efectuó en otra depresión kárstica, en las cercanías de El Angliru, cubierta por arcillas y bloques. La vegetación es la propia de un pastizal montano (un tanto nitrificado y acidificado) rodeado por afloramientos rocosos, con algunos ejemplares de Genista hispanica subsp. occidentalis, Ribes alpinum, Berberis vulgaris subsp. cantabrica y Rhamnus alpi$n a$. Se perforó el suelo (cryorthent típico) y el depósito hasta alcanzar la roca madre a unos $100 \mathrm{~cm}$, y se extrajeron $36,4 \mathrm{~kg}$ de material que sirvieron para la recuperación de 0,8047 gramos de carbón (figura 5). De nuevo, los fragmentos de angiospermas sin identificar fueron muy altos: 83 piezas de nimio tamaño y mayormente vitrificadas. Sin embargo, el resto correspondió a taxones potencialmente arbóreos, en mayor medida de Taxus baccata (78 piezas con un peso de 0,217 g), con algunas identificaciones también de Salix, Betula, Quercus (planocaducifolio) y Fraxinus, además de las arbustivas Berberis, Corylus, Prunus, Ericaceae y Leguminosae.

Las dataciones, todas ellas realizadas a carbones de especies arbóreas, arrojaron una edad entre 3.355 y 3.450 años BP para las 6 muestras de ARAMO 2 , mientras que la única de ARAMO 1 es subactual. Por tanto, los datos corroboran los conocimientos arqueológicos que señalan la Edad del Bronce como un momento esencial en la puesta en uso de las cumbres a partir del pastoralismo y la consecuente deforestación, así como por la minería, la construcción de elementos funerarios y místicos-religiosos, la caza y la recolección (Blas, 2012; 2013; 2014; Blas y Rodríguez, 2015). Efectivamente, el fuego, la quema del bosque, ha tenido un papel fundamental en la colonización de las tierras altas y los cambios de la cubierta vegetal. En definitiva, el conocimiento 
Figura 5. Perfil de los sondeos y peso de los carbones en gramos

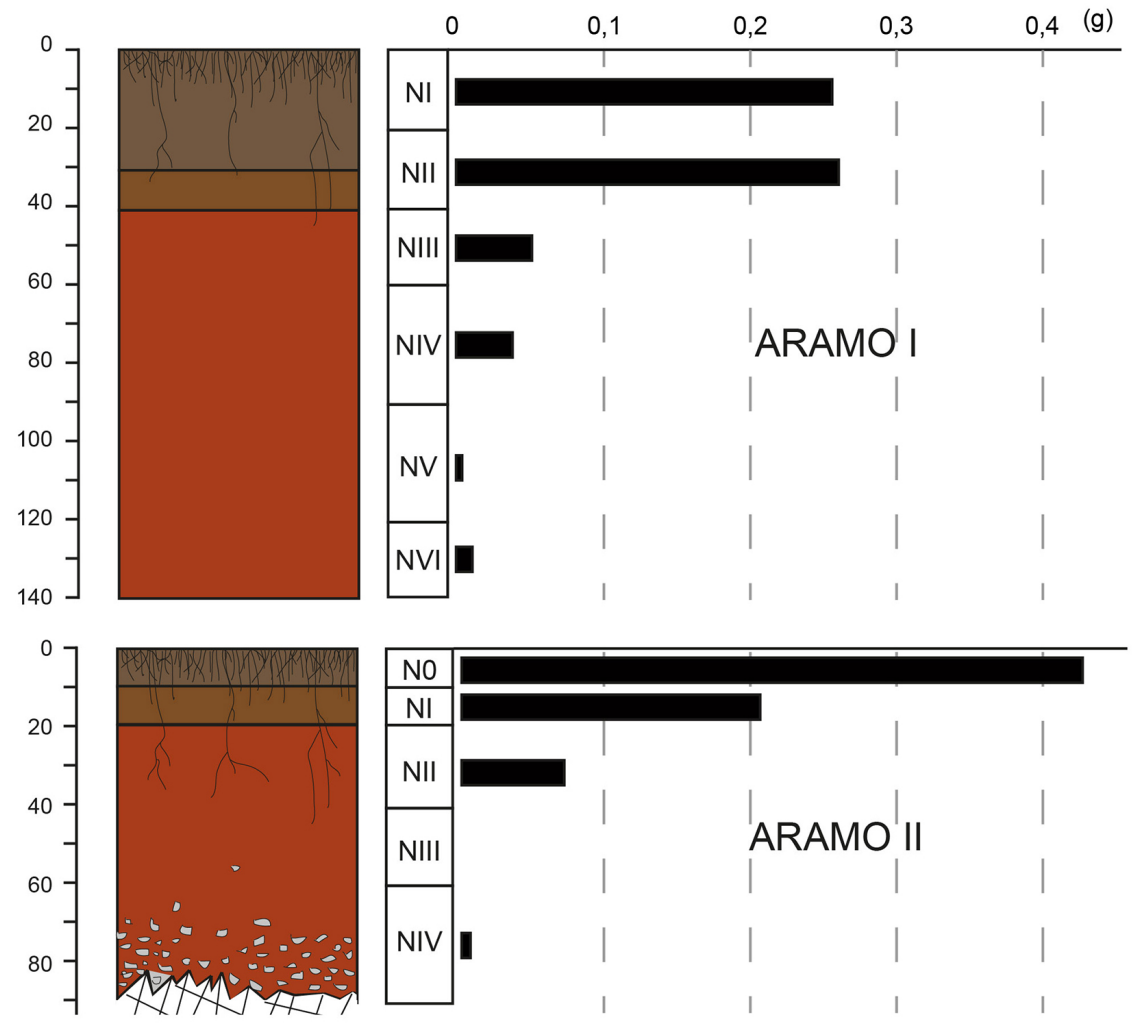

Fuente: modificado de Beato et al. (2019a).

del origen de los pastos del Aramo los convierte, mucho más si cabe, en un patrimonio cultural.

\subsection{Historia reciente del patrimonio cultural}

Buena parte de los pastos de montaña cantábricos no están sujetos a regímenes de propiedad privada, sino que forman parte de los montes comunales. El origen de esta forma de aprovechamiento colectivo no está documentado hasta la Edad Media, especialmente al poner en manos de vecindades las tierras ocupadas y puestas en explotación (Maceda, 1985; Rodríguez Vigil, 2017). Entendemos que la limitación estacional y topográfica de su usufructo en los medios de montaña habrá servido también a su explotación comunal, con una inercia histórica quizás anterior incluso a la romanización. No por ello, los montes dejan de ser un recurso valioso, como lo muestran los múltiples conflictos históricos que han ocasionado, así como la evolución de la legislación 
general, regional e incluso local hasta nuestros días, amparados como Montes de Utilidad Pública (López, 2007). En efecto, el papel de estos espacios convertidos en pastizales (algunos incluso en espacios agrícolas en tiempos de fuerte presión demográfica) y aprovisionadores de otros recursos, como el rozo, ha desempeñado un rol fundamental en la subsistencia de pueblos y aldeas, así como de sus territorios y paisajes. En todo caso, se trata no solo de un legado económico, sino también sociocultural, ligado a una gran historia de usos y costumbres que puede arrojar luz en la resolución de conflictos actuales (Vázquez, 2019).

A pesar de la colonización neolítica de la montaña cantábrica favorecida por la benignidad climática holocena, no será hasta la Edad Media cuando se incremente de una forma sustancial la presión sobre el medio, tal y como ha ocurrido en otras zonas montañosas peninsulares como los Pirineos, lo que generó estructuras territoriales que pervivieron en buena medida hasta nuestros días (Blas, 2012; Cunill, 2010; Beato et al., 2019b; García-Ruiz et al., 2015; Pérez-Obiol et al., 2016). No obstante, durante los siglos XIX y XX el crecimiento demográfico de los pueblos impuso una exigencia absoluta sobre sus dominios territoriales y unas pautas culturales que han mantenido los paisajes de montaña que heredamos. En aquel momento, la base económica de las casas (unidades familiares, culturales y económicas) en la Sierra del Aramo era la agricultura y la ganadería, hasta que llegó la minería y se consolidaron modelos mixtos. Los productos obtenidos no solo alimentaban a la familia y en parte a los animales, sino que pagaban rentas y compras. Las parcelas de cada casa estaban dispersas por todo el término parroquial (e incluso en alguno vecino) y tenían diferente calidad y orientación productiva.

El ganado bovino, ovino, caprino y caballar formaba parte de los recursos económicos y alimenticios de casas y aldeas. La cantidad de animales en propiedad era buena parte de la riqueza del grupo familiar. Las vacas proporcionaban leche (base de la alimentación, junto con la escanda, el maíz y las patatas), queso, carne, xatos y manteca para vender; cucho para abonar las tierras, y fuerza para el trabajo agrícola y el transporte (Fernández y Rodríguez, 2008). Los bovinos se mantenían en los prados del pueblo hasta que se abría el puerto (actualmente el 1 de junio) y se cerraban las morteras de las parroquias, esto es, un terreno comunal del pueblo donde pastaban los animales de los vecinos en los periodos equinocciales. Sin embargo, las morteras, que sobrepasan en algunos casos los $1.400 \mathrm{msnm}$, podían presentar parcelas de propiedad individual que se acotaban durante parte del año y que podían ser incluso cultivadas en tiempo de escasez. Se tiene noticia de siembra de patatas hasta en algunas majadas de los Puertos del Aramo, donde el ganado vacuno permanecía en verano pastando a su voluntad. Aunque se dice que cada vaca ya sabe cuál es la zona de pasto de su casa, era frecuente que pasaran al dominio de otro concejo o parroquia, lo que provocaba conflictos y prindas (retención de los animales hasta el pago de una sanción económica). En las majadas o mayeus, a las crías se las guardaba en vellares (bellares, según el concejo) y, para separar a los xatos de las madres y que no mamaran así la 
S. Beato; J. L. Marino; M. Á. Poblete; Los pastos de montaña de la Sierra del Aramo (Macizo Central Asturiano):

Figura 6. Construcciones ganaderas en los Puertos del Aramo: 1), 2) y 3) Ruinas de vellares con rebates en Anzalaoria (La Encelaoria) y El Baul!al. 4) Cabaña derruida en Xiniestal
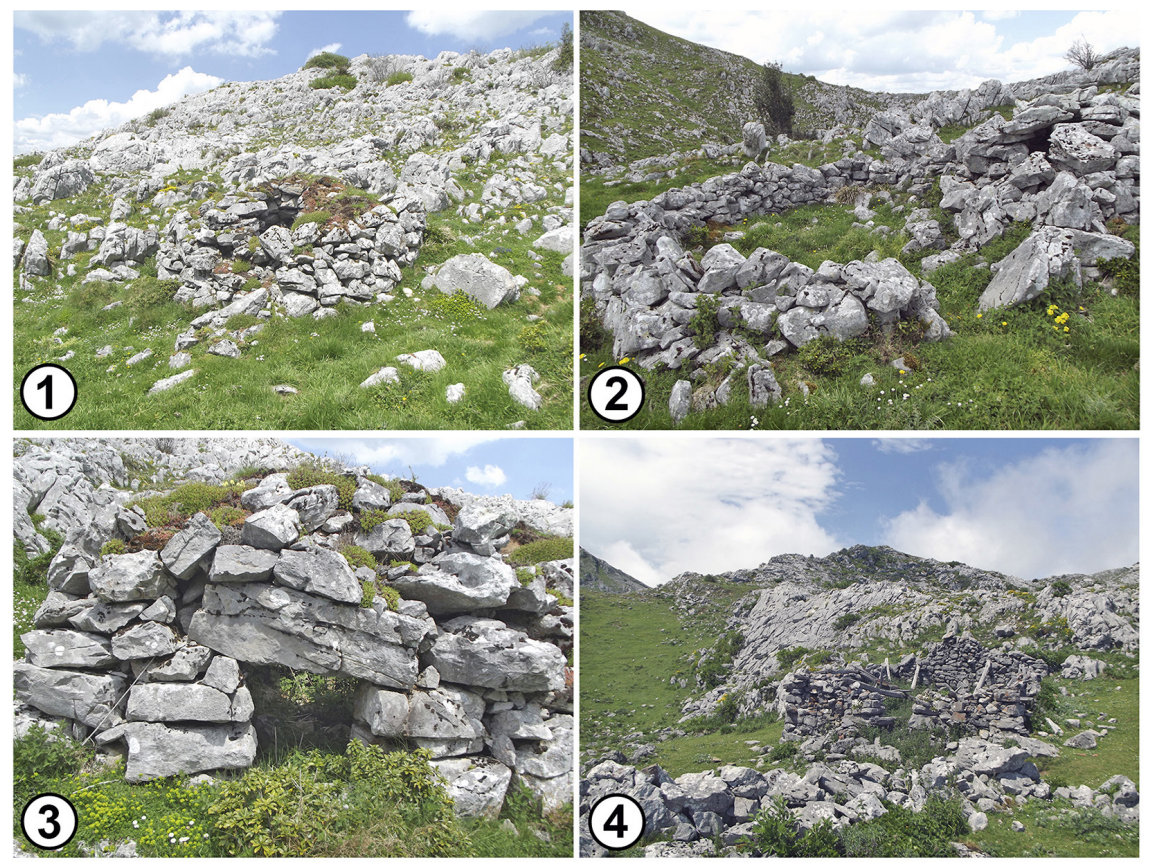

Fuente: elaboración propia.

leche, se las encerraba en corralitos, rebates o xateras (figura 6). Se trataba de pequeñas edificaciones de piedra caliza con plantas circulares y cubiertas de roca y tapinos entre las irregularidades de la peña caliar, por ejemplo, aprovechando lapiaces de agujas. Además de estas construcciones para refugio del ganado, en el paisaje de los puertos también se edificaron cabañas, cabanas o cabanones para los vaqueros, de planta rectangular y tejados de madera y teja, a veces con cuadras y pajares.

Todas las edificaciones se agrupaban en asentamientos de tipo nuclear o polinuclear denso en depresiones cercanas a charcas y fuentes (García et al., 1987). Al cuidado de las vacas, es decir, vaqueirando, no se estaba todo el día, pero sí se solía subir casi todos los días (por lo menos a por leche) y algunas noches a dormir para ahuyentar a los lobos y a establecer vínculos sociales con vecinos de otras parroquias. Cuando se cerraban los pastos del Aramo (normalmente a finales de agosto), las vacas bajaban a pastar de nuevo a la mortera una vez que había sido reabierta.

Por otro lado, ovejas y cabras se agrupaban en veceras. Se trataba de sistemas de turnos en los que una casa aportaba una persona para que trabajara durante todo el día de pastor de un rebaño de ovejas o cabras formado por los animales 
de varias casas que subían a los puertos. Las ovejas proporcionaban lana para elaborar todo tipo de prendas de vestir e ingresos a partir de su venta, o de corderos y ovejas gordas. Las cabras gruesas y los cabritos también se vendían en el mercado de Pola de Lena, e incluso las flacas, para la gente más necesitada y con menos dinero. Las pieles servían para fabricar útiles como botas, zurrones o alfombras. Los caballos no se hicieron populares hasta hace pocas décadas - tenían precios privativos-, cuando comenzaron a compartir los pastos del Aramo.

Así pues, el paisaje de hoy es el resultado de un género de vida y una organización socioeconómica y territorial diferente, donde la supervivencia dependía de un uso preciso, exhaustivo, de los recursos disponibles, con una gran relevancia de lo comunal. Los topónimos, otro destacado patrimonio cultural, mencionan especies, formaciones vegetales y paisajes desaparecidos en muchos casos, así como usos relacionados con todo ello (Viejo, 1992; 1998; 1999; 2003; Díaz Sariego, 2000; Pedregal, 2006; Menéndez, 2014). Felechal, Felguera, La Carbayosa, Carbayedo, La Nogal, La Mostayal, La Gamonal, Collá del Fresno, Fuente La Faya, Fuente El Abedul, Arandanal, Xiniestal, La Ablanosa, El Ablanedo, Salguerosa, Pico La Encina, Acebal, Los Acebos, Cantu el Acibu, Ortigales, Ortigoso, El Ortigal y un sinfín de denominaciones, con variantes léxicas y fonéticas locales, nos muestran un mosaico desaparecido en gran medida y creado por grupos humanos vinculados fuertemente a la tierra, especialmente a partir del control de la sucesión vegetal mediante el fuego y los usos tradicionales del territorio (Rozadas, La Roza, La Quema, Nava, La Castañar, La Peral). Estos nombres quedarán, por tanto, como únicos testigos de la intensa vida que se produjo en los Puertos del Aramo, junto a las ruinas de brañas y majadas (que pueden hundir sus raíces en lo más profundo de la historia), y los relatos y documentos sobre los aprovechamientos comunales de los pastos (figura 7).

En la actualidad, la matorralización avanza sobre los pastos precediendo la recuperación de la cubierta arbórea (Beato et al., 2019b). A esto contribuyen indudablemente el despoblamiento rural, el fin de las actividades tradicionales (rozas, pequeñas quemas controladas), la organización y los conflictos de usos de los Montes de Utilidad Pública, la desaparición de los pequeños propietarios de ganado variado y la aparición de grandes ganaderos dedicados a la producción cárnica de vacuno (González et al., 2018). En definitiva, todo esto requiere una reflexión profunda, toda vez que está en riesgo un importante patrimonio cultural con un origen que nos retrotrae a los primeros pobladores de las montañas asturianas. En otras zonas de montaña, como los Pirineos, se ha puesto de manifiesto la importancia del conocimiento del medio por sus pobladores y de las labores seculares para mitigar los efectos de procesos naturales y antrópicos como la erosión y la degradación de los suelos, del mismo modo que la interacción con los cambios climáticos, las modificaciones en la escorrentía y los procesos de sedimentación (GarcíaRuiz et al., 2015). 
S. Beato; J. L. Marino; M. Á. Poblete; Los pastos de montaña de la Sierra del Aramo (Macizo Central Asturiano):

Figura 7. Mapa de Montes de Utilidad Pública, brañas y majadas de la Sierra del Aramo

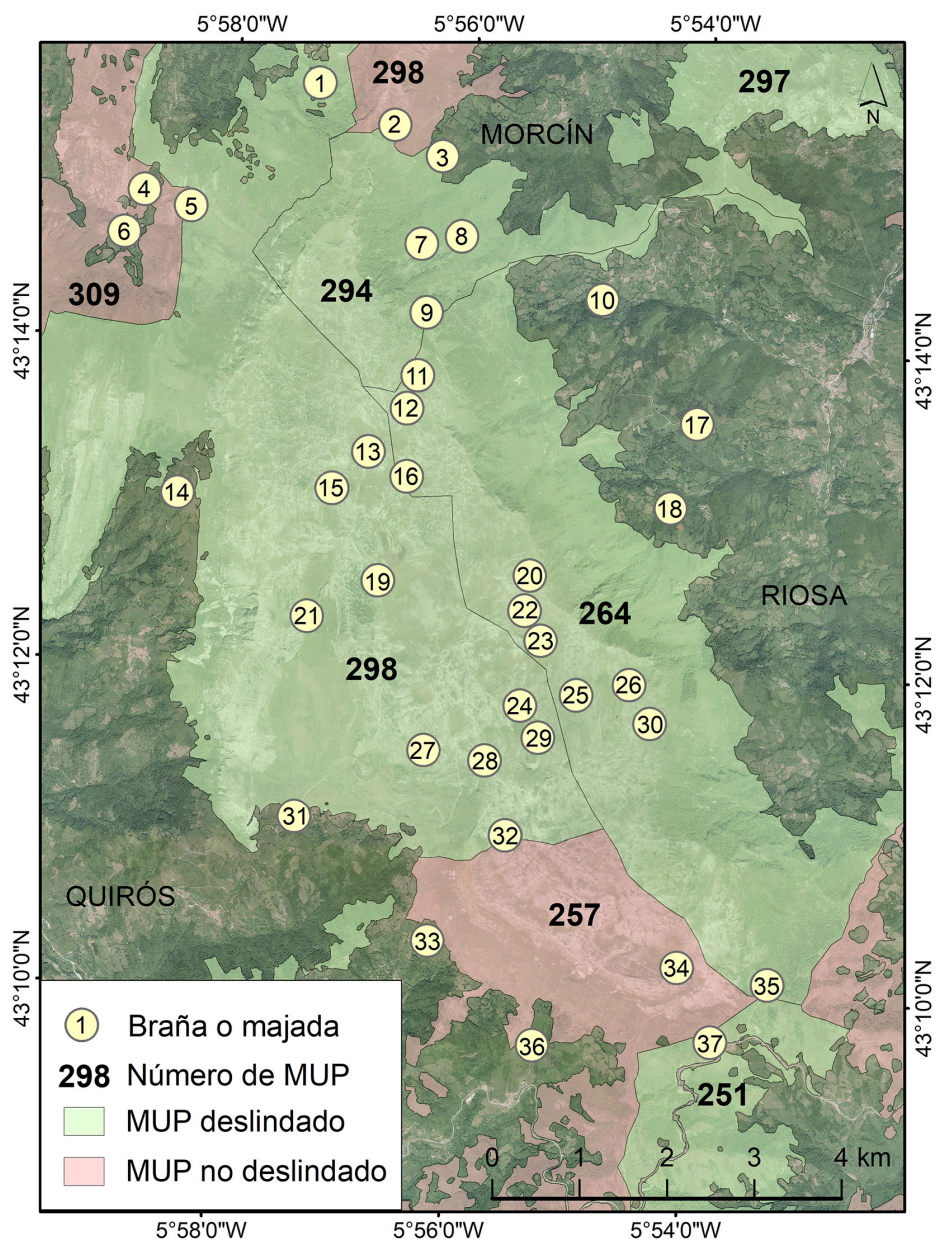

Brañas y majadas: 1. Gameo. 2. Brañace. 3. Les Bragaories. 4. Canalseca. 5. Buxana. 6. Castrillón. 7. Fonfría. 8. Los Espinos. 9. Covallos. 10. Utriel. 11. El Toyo. 12. Campalaovia. 13. Valdesiniestra. 14. Linares. 15. Fonpedrín. 16. Angleiru. 17. Solavega. 18. Code. 19. Vallongo. 20. Los Cuadrazales. 21. Covallos. 22. La Veguil! lina. 23. Robles. 24. La Xiniestal. 25. Tres La Vega La Cuaña. 26. La Covariega. 27. El Texu. 28. La Poza. 29. La Florida. 30. Ḷ̣azarandín. 31. Alba. 32. La Bargana. 33. Ordiales. 34. Los Veneros. 35. Mayeu D’Espines. 36. El Rallón. 37. Los Pumares.

Fuente: elaboración propia.

\section{Conclusiones}

Los pastos de montaña no son un mero recurso forrajero ni deben ser una simple estampa del pasado, constituyen en sí mismos refugios de biodiversidad y forman parte del mosaico paisajístico sobre el abrupto relieve cantábrico. Igualmente, son hábitats de interés comunitario en el más puro y profundo 
sentido de este adjetivo. En su gestión, están implicados los pastores y el conjunto de los vecinos de pueblos y aldeas, además de los modernos ganaderos, las asociaciones de cazadores, los grupos de desarrollo rural, los ayuntamientos concejiles y la Administración regional, hoy en día, bajo normativas estatales y europeas. Se trata de un extraordinario complejo que tiene unas raíces históricas mucho más allá de donde llega la memoria colectiva y la documentación. En la Sierra del Aramo, estos pastos, presentes ya en la Edad del Bronce, exhiben una riqueza biológica relativamente amplia, a pesar de la idiosincrasia geoecológica de esta unidad de media montaña calcárea. Buena parte de sus formaciones de porte herbáceo son hábitats de interés comunitario, en el marco de la Red Natura 2000, en concreto, de los códigos 6170, 6210, 6230, 6510, 8130 y 8210 , entre pastos carbonatados y acidificados, céspedes y comunidades glerícolas y casmófitas. A pesar del proceso generalizado de matorralización, estos pastizales conservan cierta inercia histórica, aunque comienzan a sufrir los efectos de una transformación global, entre otras razones, por la concentración del ganado y la especialización y tecnificación ganadera. La expansión del matorral y la reforestación silvestre pueden, por otro lado, homogeneizar el paisaje y provocar pérdidas culturales (cierre de caminos, ocultación y deterioro de construcciones seculares) e incrementar el patrimonio ecológico (aumento de la superficie de hábitats de interés comunitario forestales existentes, extensión y densificación de los bosques), si bien esto podrá ser valorado justamente en el futuro o con las debidas cautelas a través de escenarios y proyecciones. Sea como fuere, lo que es evidente es que el fin de la sociedad tradicional asturiana, de los usos y costumbres arcaicos, conlleva alteraciones importantes que no solo ponen en peligro la conservación del patrimonio cultural, sino que afectan también al patrimonio natural y a la biodiversidad.

En este sentido, se hace necesaria la intervención de equipos interdisciplinares que sondeen la geohistoria ambiental y cultural de las montañas asturianas, tal y como está ocurriendo en otras áreas montañosas cantábricas, pirenaicas y mediterráneas. Igualmente, se requiere la aplicación de técnicas valorativas del patrimonio que permitan a los gestores tomar decisiones acertadas. En efecto, el paisaje, el territorio, la sociedad y la naturaleza en general están en constante interrelación dinámica, lo cual dificulta mucho más si cabe el análisis y la interpretación del espacio geográfico globalizado. Así pues, el cambio de las condiciones geoecológicas en las montañas es climático y, por tanto, hidrológico, geomorfológico y biogeográfico, pero también lo es antrópico, por las intervenciones humanas en los procesos naturales y la propia modificación cultural de los grupos humanos, especialmente en la actualidad. Esta transformación es rápida e implacable y se impone al conjunto de la biosfera, por lo que no parece eficaz la generación de propuestas sectoriales o locales que no se adapten a las directrices generales. De hecho, nos sumerge en una discusión teórica entre el determinismo y el posibilismo, y filosófica entre, por un lado, el poder de la voluntad del individuo y la organización colectiva y, por el otro, la fatalidad del azar y un sistema global sin dirección posible. 
S. Beato; J. L. Marino; M. Á. Poblete; Los pastos de montaña de la Sierra del Aramo (Macizo Central Asturiano):

\section{Referencias bibliográficas}

ARgAmentería, A. (coord.) (2004). Tipificación, cartografía y evaluación de los pastos españoles: cartografía de los pastos de Asturias. Documento inédito. SEEP, INIA, SERIDA, INDUROT.

Argamentería, A.; Martínez-Martínez, A. y Martínez-Fernández, A. (2010). «Producción ecológica de pastos y forrajes frente al método convencional». Vida Rural, 303, 34-38.

ARIAS, P. (1991). De cazadores a campesinos: la transición al Neolítico en la región cantábrica. Santander: Asamblea Regional de Cantabria.

Arozena, M. E. y Molina, P. (2000). «Estructura de la vegetación». En: MeAZA, G. (dir.). Metodología y práctica de la biogeografía. Barcelona: Serbal, 77-147.

BeAto, S. (2018). El patrimonio natural de la Sierra del Aramo (Montaña Central Asturiana) y la evolución de su paisaje. Tesis doctoral inédita. Departamento de Geografía, Universidad de Oviedo.

Beato, S.; Poblete, M. Á. y Marino, J. L. (2016). «La expansión del matorral y su caracterización biogeográfica en la Sierra del Aramo (Montaña Central Asturiana, España)». En: Gómez Zotano, J.; Arias García, J.; Olmedo Cobo, J. A. y SerraNO Montes, J. L. (eds.). Avances en biogeografía. Areas de distribución: entre puentes y barreras. Granada: Ediciones de la Universidad de Granada, Tundra, 494-502.

- (2017). «El paisaje vegetal y los hábitats forestales de interés comunitario en la Montaña Central Asturiana». Cuadernos Geográficos, 56 (1), 26-52.

Beato, S.; Poblete, M. Á. y Cunill, R. (2019a). "Taxus baccata en la Sierra del Aramo (Macizo Central Asturiano)». Boletín de la Asociación de Geógrafos Españoles, 81 (2.772). <http://dx.doi.org/10.21138/bage.2772>

Beato, S.; Poblete, M. Á. y Marino, J. L. (2019b). «La dinámica del paisaje en la Sierra del Aramo (Macizo Central Asturiano): procesos naturales y antrópicos». Pirineos, 174, e041. <https://doi.org/10.3989/pirineos.2019.174001>

Bertrand, G. (1966). «Pour une étude géographique de la végétation». Revue Géographique des Pyrénées et du Sud-Ouest, XXXVII, fasc. 2, 129-143.

BLAS, M. A. de (2012). "Beneficio y consagración de las cumbres: el caso de "Los Fitos" y la concurrencia Neolítico-Bronce antiguo en el área megalítica de La Cobertoria, Asturias». En: MuÑIZ, J. R. (coord.). Ad orientem. Del final del paleolitico en el norte de España a las primeras civilizaciones del Oriente Próximo. Estudios en homenaje al profesor Juan Antonio Fernández-Tresguerres Velasco. Oviedo: Ediciones de la Universidad de Oviedo, Ménsula Ediciones, 307-347.

- (2013). «IV.o milenio aC: los monumentos sepulcrales del Puerto de la Cobertoria (Quirós) y el dominio de las cumbres por las sociedades neolíticas». En: BLAS, M. Á. de (coord.). De neandertales a albiones: cuatro lugares esenciales de la Prehistoria en Asturias. Oviedo: Real Instituto de Estudios Asturianos, 69-138.

- (2014). «El laboreo del cobre en la Sierra del Aramo (Asturias) como referente cardinal de la minería prehistórica en la región cantábrica». Cuadernos de Prehistoria y Arqueología, 24, 45-84.

Blas, M. Á. de y Rodríguez, F. (2015). «La cuestión campaniforme en el Cantábrico central y las minas de cobre prehistóricas de la Sierra del Aramo». Cuadernos de Prehistoria y Arqueología, 41, 165-179.

Braun-Blanquet, J. (1979). Fitosociología. Bases para el estudio de las comunidades vegetales. Madrid: Blume. 
Bronk, C. (2017). «OxCal [WWW program] version 4.3». Oxford Radiocarbon Accelerator Unit: University of Oxford. Disponible en <https//c14.arch.ox.ac.uk/oxcal/ OxCalhtml>.

Corbera, M. (2006). «Organización de los espacios de pastos en la montaña atlántica: los nombres, las formas y las funciones». Ería. Revista Cuatrimestral de Geografía, 92, 275-292.

Cubas, M.; Altuna, J.; Álvarez-Fernández, J.; Armendáriz, E.; Fano, M. A.; López Dóriga, I.; Mariezkurrena, K.; Tapia, J.; Teira, L. y Arias, P. (2016). "Re-evaluating the Neolithic: The Impact and the Consolidation of Farming Practices in the Cantabrian Region (Northern Spain)». Journal of World Prehistory, 29 (1), 79-116.

CuniLl, R. (2010). Estudi interdisciplinari de l'evolució del limit superior del bosc durant el periode holocènic a la zona de Plaus de Boldis-Montarenyo, Pirineu central català. Pedoantracologia, palinologia, carbons sedimentaris i fonts documentals. Tesis doctoral inédita. Universitat Autònoma de Barcelona.

Cunill, R.; Soriano, J. M.; Bal, M. C.; Pèlachs, A. y Pérez-Obiol, R. (2012). "Holocene treeline changes on the south slope of the Pyrenees: a pedoanthracological analysis». Vegetation History and Archaeobotany, 21, 373-384.

Cunill, R.; Soriano, J. M.; Bal, M. C.; Pèlachs, A.; Rodríguez, J. M. y PérezObiol, R. (2013). «Holocene high-altitude vegetation dynamics in the Pyrenees: a pedoanthracology contribution to an interdisciplinary approach». Quaternary International, 289, 60-70. <https://doi.org/10.1016/j.quaint.2012.04.041>

DíAz, T. E. (2009). "Caracterización de los Distritos Biogeográficos del Principado de Asturias (Norte de España)». En: Llamas, F. y Acedo, C. (eds.). Botánica Pirenaico-Cantábrica en el siglo XXI. León: Área Publ. Univ. León, 423-455.

- (2014). «Mapas de vegetación de las series, geoseries y geopermaseries de España. 1.250.000: Asturias». Global Geobotany, 3, 1-34.

DíAz, T. E. y FernándeZ, J. A. (1994). «El paisaje vegetal de Asturias». Itinera Geobotánica, 8, 5-242.

- (2006). «Biogeografía de Asturias: Bases para su actualización». Actas I Congreso de Estudios Asturianos. Oviedo, 10-13 mayo 2006. Oviedo: R.I.D.E.A.

Díaz Sariego, M. (2000). Toponimia del Conceyu de Riosa. Oviedo: Academia de la Llingua Asturiana, Gobiernu del Principáu d'Asturies.

FERnÁndeZ, F. J. (2017). "Ganadería en Asturias en la primera Edad Media». En: Gómez-Pantoja, J. (dir.). Los rebaños de Gerión. Madrid: Casa de Velázquez, $139-158$.

FERNÁNDEZ GARCÍA, F. (2006). «La quiebra del modelo histórico de organización de la Montaña Cantábrica». En: Delgado-Viñas, C. (ed.). La Montaña Cantábrica, una montaña viva. Santander: Cátedra Cantabria, Parlamento de Cantabria y Universidad de Cantabria, 79-98.

Fernández, R. y RodrígueZ, A. (2008). Apuntes Etnográficos del Concejo de Quirós. Agricultura y ganadería (Tierra). Quirós (Asturias): Ayuntamiento de Quirós.

FIDALGO, C. (1997). «El trabajo de campo en biogeografía». Didáctica Geográfica, 2, 33-44.

GarCÍA, A. (2003). «La trashumancia en Asturias». En: ElíAs, L. y NovOA, F. (eds.). Un camino de ida y vuelta: la trashumancia en España. Barcelona: Lunwerg, 95-107.

García, F.; DíAZ, S. y SAGASTI, J. (1987). «Las construcciones ganaderas de la Sierra del Aramo». Astura, 6, 13-22. 
García FernándeZ, J. (1980). Sociedad y organización del espacio tradicional en Asturias. Gijón: Silverio Cañada.

- (1990). «La organización tradicional del espacio rural en el área cantábrica». En: García, L. V.; Sierra, J. M.; Fuente, R.; GonzÁlez, R. (comp.). Los espacios rurales cantábricos y su evolución. Santander: Universidad de Cantabria, 13-31.

García-Ruiz, J. M.; López-Moreno, J. I.; Lasanta, T.; Vicente-Serrano, S. M.; González-Sampériz, P.; Valero-Garcés, B. L.; Sanjuán, Y.; Beguería, S.; Nadal-Romero, E.; Lana-Renault, N. y GómeZ-Villar, A. (2015). «Los efectos geoecológicos del cambio global en el Pirineo Central español: una revisión a distintas escalas espaciales y temporales». Pirineos, 170, e012. <http://dx.doi.org/10.3989/Pirineos.2015.170005>

González, J. A.; Celaya, R.; Fraser, M. D.; Osoro, K.; Ferreira, L. M. M., FerNÁNDEZ, F.; GONZÁlEZ, B. y RosA, R. (2018). «Agroforestry Systems in Northern Spain: The Role of Land Management and Socio-economy in the Dynamics of landscapes». En: Dagar, J. C. y Tewari, V. P. (eds.). Agroforestry, Anecdotal to Modern Science. Singapur: Springer Nature, 189-215.

INDUROT (1994). Cartografía temática ambiental. Mapa de vegetación. Escala 1:25.000. Consejería de Medio Ambiente, Ordenación del Territorio e Infraestructuras del Gobierno del Principado de Asturias.

La Nueva España (20/09/2009). La sentencia contra los prindajes abre una tregua en la "guerra de pastos» del Aramo.

- (28/08/2013). Los ganaderos de Lena y Quirós resuelven el histórico conflicto de pastos del Aramo.

- (20/02/2018). Quirós alegará contra la norma que regula el uso de los pastos en el Aramo.

- (02/09/2020). Fin del conflicto por Güeria: Lena gana 300 hectáreas de monte público a Quirós.

La Voz del Trubia (18/02/2018). Guerra de pastos entre Lena y Quirós por los montes del Aramo.

- (19/02/2018). El fallo que quita a Quirós pastos del Aramo estuvo oculto 10 años.

- (31/07/2018). Luz verde al polémico deslinde del puerto de Andrúas, en Quirós

- (03/09/2020). Varapalo judicial a los ganaderos de Quirós, que pierden pastos en Güeria y Andrúas.

López, A. (dir.) (2007). Montes de Utilidad Pública en el Principado de Asturias. Oviedo: Gobierno del Principado de Asturias.

MacedA, A. (1985). "Distribución espacial de las categorías de montes colectivos en Asturias». Ería, Revista Cuatrimestral de Geografía, 9, 113-129.

MAPAMA (Dirección General de Desarrollo Rural) (2018). Mapa Forestal de España de máxima actualidad 1:25.000 (MFE25). Ministerio para la Transición Ecológica. Disponible en <https://www.miteco.gob.es/es/cartografia-y-sig/ide/descargas/biodiversidad/mfe.aspx $>$.

Marino, J. L.; Beato, S. y Poblete, M. Á. (2017). «El patrimonio vegetal en los Arribes del Duero zamoranos: las formaciones de enebral Juniperus oxycedrus L. subsp. badia (H. Gay) Debeaux». Cuadernos Geográficos, 56 (3), 90-115.

MartíneZ, L. C. (2016). Los paisajes de la alta montaña central de Asturias. Oviedo: Ediciones Universidad de Valladolid, Ediuno (Ediciones de la Universidad de Oviedo).

MAYOR, M. (1996). Indicadores ecológicos y grupos socioecológicos en el Principado de Asturias (Sierra del Aramo). Oviedo: Universidad de Oviedo. 
Mayor, M.; Andrés, J.; Martínez, G.; Navarro, F. y Díaz, T. E. (1973). «Estudio de los pastizales de diente y de siega en algunas localidades de la Cordillera Cantábrica con especial atención al comportamiento ecológico de Festuca hystrix Boiss». Revista de la Facultad de Ciencias de la Universidad de Oviedo, 14 (2), 161-171.

Mayor, M.; Díaz, T. E.; Navarro, F.; Martínez, G. y Benito, M. F. (1977). «Los pastizales naturales del Sector Iberoatlántico: su dinamismo y distribución geográfica». Trab. Dep. Bot. Univ. Oviedo, 1, 3-16.

Mayor, M.; Díaz, T. E.; Fernández, J. A. y Lastra, J. J. (1978). «Estudio Ecológico del "Cervuno" (Nardus stricta L.) en la Cordillera Cantábrica». Pastos, 8 (2), 183-194.

Menéndez, M. (2014). Palabras y cosas de Bermiego (Quirós) (1950-1961). Edición de Xulio Viejo Fernández. Oviedo: Ediciones de la Universidad de Oviedo.

Muñoz, J. (1982). Geografía de Asturias. Oviedo: Ayalga Ediciones.

- (2000). «El factor climático en los paisajes de montaña españoles». En: MARTínEz DE PISÓN, E. (dir.). Estudios sobre paisaje. Madrid: Fundación Duques de Soria y Universidad Autónoma de Madrid.

Navarro, F. (1974a). Estudio de la flora y vegetación de la Sierra del Aramo y sus estribaciones (Asturias). Tesis doctoral inédita. Facultad de Ciencias, Universidad de Oviedo.

- (1974b). "La vegetación de la Sierra del Aramo y sus estribaciones (Asturias)». Revista de la Facultad de Ciencias de la Universidad de Oviedo, 15 (1), 111-243.

Ortega VAlCÁRCEL, J. (1989). "La economía de montaña, una economía de equilibrio». Ería, Revista Cuatrimestral de Geografía, 19, 115-128.

Panareda, J. M. (1996). "Cartografía de la Vegetación». Serie Geográfica, 6, 11-34.

Pedregal, M. A. (2006). «La creación del espacio histórico en Tene (Quirós, Asturias)». Territorio, Sociedad y Poder, 1, 157-190.

Pérez-Obiol, R.; García, J. C.; Pèlachs, A.; Pérez, A. y Soriano, J. M. (2016). "Landscape dynamics and fire activity since $6740 \mathrm{cal} \mathrm{yr} \mathrm{BP}$ in the Cantabrian region (La Molina peat bog, Puente Viesgo, Spain)». Quaternary Science Reviews (135), 65-78.

Poblete, M. Á.; Beato, S. y Marino, J. L. (2020). «Hábitats arbustivos de interés comunitario en la Sierra del Aramo (Macizo Central Asturiano)». En: CARRACEDO, V.; García-Codron, J. C.; Garmendia, C.; y Rivas, V. (eds.). Conservación, Gestión y Restauración de la Biodiversidad. XI Congreso Español y I Congreso Iberoamericano de Biogeografía. Santander (España), 22-25 de junio, 319-328. Santander: Asociación de Geógrafos Españoles (AGE).

Reimer, P. J.; Bard, E.; Bayliss, A.; Beck, J. W.; Blackwell, P. G. et al. (2013). "IntCal13 and MARINE13 radiocarbon age calibration curves 0e50,000 years cal BP». Radiocarbon, 55 (4), 1.869-1.887.

Remón, J. L.; Gómez, D. y García-GonzÁlez, R. (2009). «6170 Pastos de alta montaña caliza». En: VV.AA. Bases ecológicas preliminares para la conservación de los tipos de hábitat de interés comunitario en España. Madrid: Ministerio de Medio Ambiente, y Medio Rural y Marino.

Reiné, R. (2009). «Prados de siega de montaña (Arrhenatherion)». En: VV.AA. Bases ecológicas preliminares para la conservación de los tipos de hábitat de interés comunitario en España. Madrid: Ministerio de Medio Ambiente, y Medio Rural y Marino.

Rivas-Martínez, S. (2005). «Avances en Geobotánica». Discurso de Apertura del Curso Académico de la Real Academia Nacional de Farmacia del año 2005. Disponible en <http://www.globalbioclimatics.org/book/ranf2005.pdf> [Consulta: 15 de mayo de 2015]. 
Rivas-Martínez, S.; Penas, A.; Asensi, A.; Costa, M.; Llorens, L.; Pérez de Paz, P.L.; Loidi, J.; Díaz, T. E.; Izco, J.; Ladero, M.; Fernández, F. y SÁnChez, D. (2003). Atlas y manual de los hábitats de España. Madrid: Ministerio de Medio Ambiente de España. Dirección General de Conservación de la Naturaleza.

Rodríguez, F. (1989). La organización agraria de la Montaña Central Asturiana. Oviedo: Principado de Asturias, Consejería de Educación, Cultura y Deportes.

Rodríguez Vigil, J. L. (2017). La mitad olvidada de Asturias. Los montes comunales de Asturias. Historia, situación actual, dimensiones y régimen jurídico. Oviedo: Real Instituto de Estudios Asturianos.

SCHWEINGRÜBER, H. S. (1990a). Anatomie europäischer Hölzer. Stuttgart: W.S.L.F.N.P.

- (1990b). Microscopic Wood Anatomy. Birmensdorf: Swiss Federal Institute for Forest, Snow and Landscape Research.

Serrano, E. (2012). "Montañas, paisaje y patrimonio». Nimbus: Revista de Climatología, Meteorología y Paisaje, 29-30, 701-718.

VÁZQUEZ, I. (2019). «El archivo histórico, una fuente de conocimiento para la gestión actual de pastos comunales». Pirineos, 174, e045. <https://doi.org/10.3989/pirineos.2019.174005>

Vernet, J. L.; Ogereau, P.; Figueiral, I.; Machado, C. y Uzquiano, P. (2001). Guide d'identification des charbons de bois préhistoriques et récents. Sud-Ouest de l'Europe, France (Péninsule Ibérique et Îles Canaries). París: CNRS Editions.

VIEjo, X. (1992). Dellos fitónimos quirosanos. Lletres Asturianes, 45. Oviedo: Academia de la Llingua Asturiana, Principáu d'Asturies.

- (1998). Toponimia de Quirós (2). Llugar de Tene. Oviedo: Academia de la Llingua Asturiana, Conseyería de Cultura del Principáu d'Asturies.

- (1999). «D’onomástica asturiana antigua: un exemplu de pervivencia na topoinimia». En: Corona Spicea, in memoriam Cristóbal Rodríguez Alonso. Oviedo: Universidad de Oviedo, 649-664.

- (2003). «Notes d'hidrotopoinimia quirosana». Revista de Filoloxía Asturiana, vol. 3-4, 267-268.

VV.AA. (2009). Bases ecológicas preliminares para la conservación de los tipos de hábitat de interés comunitario en España. Madrid: Ministerio de Medio Ambiente, y Medio Rural y Marino.

YERA, J. y ASCASO, J. (2009). «Pastos vivaces mesofíticos y mesoxerofíticos sobre sustratos calcáreos de Festuco-Brometea». En: VV.AA. Bases ecológicas preliminares para la conservación de los tipos de hábitat de interés comunitario en España. Madrid: Ministerio de Medio Ambiente, y Medio Rural y Marino. 